GA-A16689 WhJ

\title{
ELECTRON-CYCLOTRON-HEATING RESULTS ON JFT-2, AND THEIR IMPLICATIONS FOR THE DOUBLET III ECH DESIGN
}

by

R. PRATER and C. P. MOELLER

MARCH 1982 


\section{DISCLAIMER}

This report was prepared as an account of work sponsored by an agency of the United States Government. Neither the United States Government nor any agency Thereof, nor any of their employees, makes any warranty, express or implied, or assumes any legal liability or responsibility for the accuracy, completeness, or usefulness of any information, apparatus, product, or process disclosed, or represents that its use would not infringe privately owned rights. Reference herein to any specific commercial product, process, or service by trade name, trademark, manufacturer, or otherwise does not necessarily constitute or imply its endorsement, recommendation, or favoring by the United States Government or any agency thereof. The views and opinions of authors expressed herein do not necessarily state or reflect those of the United States Government or any agency thereof. 


\section{DISCLAIMER}

Portions of this document may be illegible in electronic image products. Images are produced from the best available original document. 


\section{DISCLAIMER}

This report was prepared as an account of work sponsored by an agency of the United States Government. Neither the United States Government nor any agency thereof, nor any of their employees, makes any warranty, express or implied, or assumes any legal liability or responsibility for the accuracy, completeness, or usefulness of any information, apparatus, product, or process disclosed, or represents that its use would not infringe privately owned rights. Reference herein to any specific commercial product, process, or service by trade name, trademark, manufacturer, or otherwise, does not necessarily constitute or imply its endorsement, recommendation, or favoring by the United States Government or any agency thereof. The views and opinions of authors expressed herein do not necessarily state or reflect those of the United States Government or any agency thereof. 
GA-A16689

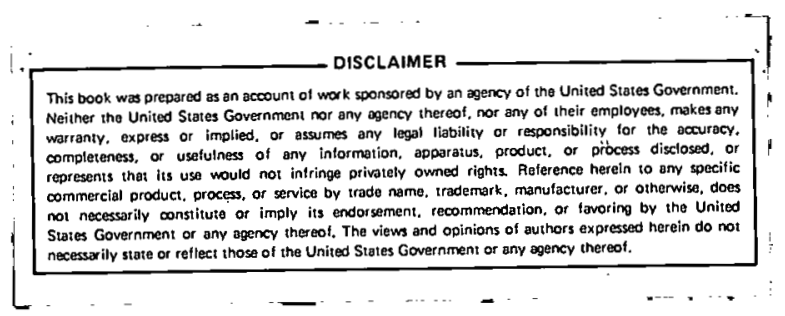

\title{
ELECTRON-CYCLOTRON-HEATING RESULTS ON JFT-2, AND THEIR IMPLICATIONS FOR THE DOUBLET III ECH DESIGN
}

\author{
by \\ R. PRATER and C. P. MOELLER
}

This is a preprint of a paper to be presented at the Third Joint Varenna-Grenoble International Symposium on Heating in Toroidal Plasmas, March 22-27, 1982 at Grenoble, France.

\author{
Work supported by \\ Department of Energy \\ Contract DE-AT03-76ET51011
}

GENERAL ATOMIC PROJECT 3235 MARCH 1982

DISTRIBUTIOH OF THIS DOCUMENT IS UNLIMIFED

Mord 
ELECTRON CYCLOTRON HEATING RESULTS ON JFT-2, AND THEIR

IMPLICATIONS FOR THE DOUBLET III ECH DESIGN*

Ronald Prater and Charles P. Moeller

General Atomic Company, P. O. Box 81608, San Diego, CA 92138 USA

Abstract

Electron cyclotron heating experiments are described in which 28 $\mathrm{GHz}$ microwave power is injected into the JFT-2 tokamak. Ordinary mode power injected from the low field side increased the central electron temperature from $600 \mathrm{eV}$ to $1000 \mathrm{eV}$ with $110 \mathrm{~kW}$, for densities below the ordinary mode cutoff density of $1.0 \times 1013 \mathrm{~cm}^{-3}$. Extraordinary mode power launched obliquely from the high field side increased the temperature from $600 \mathrm{eV}$ to $1200 \mathrm{eV}$ with $85 \mathrm{~kW}$, for densities well below the extraordinary mode cutoff density, and effective heating was maintained close to the cutoff density of $1.6 \times 1013 \mathrm{~cm}^{-3}$. The extraordinary mode launched obliquely was also found to heat more efficiently and to a hitgher density than the extraordinary wave launched perpendicularly. On this basis, the Doublet III ECH experiments which will use up to $2 \mathrm{MW}$ of $60 \mathrm{GHz}$ power are designed to make use of oblique inside launch of a pure extraordinary mode. The waveguide transmission system to accomplish this is discussed.

\section{Introduction}

Electron cyclotron heating $(E C H)$ has a number of technological advantages which make it useful in plasma confinement devices. Under suitable conditions the waves are strongly damped, resulting in a highly

\footnotetext{
*This work was supported by the U.S. Department of Energy, Contract DEAT03-76ET51011. The JFT-2 experiments were partially supported by the Japanese Atomic Energy Research Institute.
} 
local heat deposition. This effect can be expected to provide very efficlent heating in tokamaks, for example, since the heat can be deposited at the plasma center; simulations have shown that central ECH requires only one third to one half the power and a fourth the energy of neutral beam heating to raise an INTOR-sized plasma to ignition, due to the much broader heat deposition profile of neutral beam heatingl. Likewise, ECH can be used to broaden the temperature profile in tokamaks, which under an ohmic equilibrium leads to a current density profile much wider than that typical of tokamaks heated only by ohmic currents. These broadened profiles may in turn lead to higher beta operation of the tokamak, if they are frozen in by high power heating.

ECH appears to be useful in a varlety of other applications in tokamaks, including preionization and startup 2,3 , disruption elimination through suppression of internal kink modes ${ }^{4}$, and current drive 5,6 . ECH also finds application in other geometries, for example plasma generation and heating in stellarators, ring formation and plasma heating in EBT's, and thermal barrier generation and heating in tandem mirrors.

Until quite recently, ECH was severely limited by the avallability of high power sources. With the advent of the gyrotron, heating experiments were performed on a number of tokamaks, but interpretation of the results of most of these experiments has been difficult because a mixture of wave modes were launched. The experiments reported here, which were performed on the JFT-2 tokamak at the Japanese Atomic Energy Research Institute, were designed to test the propagation and damping of pure modes in order to facilitate comparison with theory. As the theory becomes more completely validated, new ECH experiments will be easier to design with some certainty.

ECH Experiments on the JFT-2 Tokamak 7,8

Two separate sets of experiments were performed. In the first, a pure ordinary wave was launched nearly perpendicular to the toroldal field from the large major radius (low toroldal fleld) side of the plasma. In the second, a pure extraordinary wave was launched obliquely into the plasma from the high field side; alternatively, a mixture of the two modes could be launched perpendicularly. The power source was a $28 \mathrm{GHz}$ gyrotron manufactured by Viarian Associates, which was capable of $200 \mathrm{~kW}$ output for pulse lengths of up to $40 \mathrm{msec}$. Most of the data was taken with input power at the plasma of 80 to $110 \mathrm{kl}$ due to inefficiencies in the transmission system.

The waveguide setups for these experiments are shown in Fig. 1. Since the gyrotron output is primarily in the circular electric TE 02 mode, the power is converted immediately to the $\mathrm{TE}_{10}$ mode in the rectangular waveguide in order to facilitate generation of the linearly polarized or elliptically polarized waves required for the launching of pure modes. The $T E_{10}$ mode is rather lossy in fundamental waveguide, but this approach was chosen in splte of the losses because of the ease with wh1ch the desired modes can be launched.

The JFT-2 tokamak has a major radius of $0.9 \mathrm{~m}$ and a minor radius of $0.25 \mathrm{~m}$, and in these experiments the plasma current was $70-75 \mathrm{kA}$ and the toroidal field was between $0.86 \mathrm{~T}$ and $1.12 \mathrm{~T}$. The electron temperature without ECH is typically $600 \mathrm{eV}$. The basic diagnostics used in determining the heating effects are the Thomson scattering system and a soft 


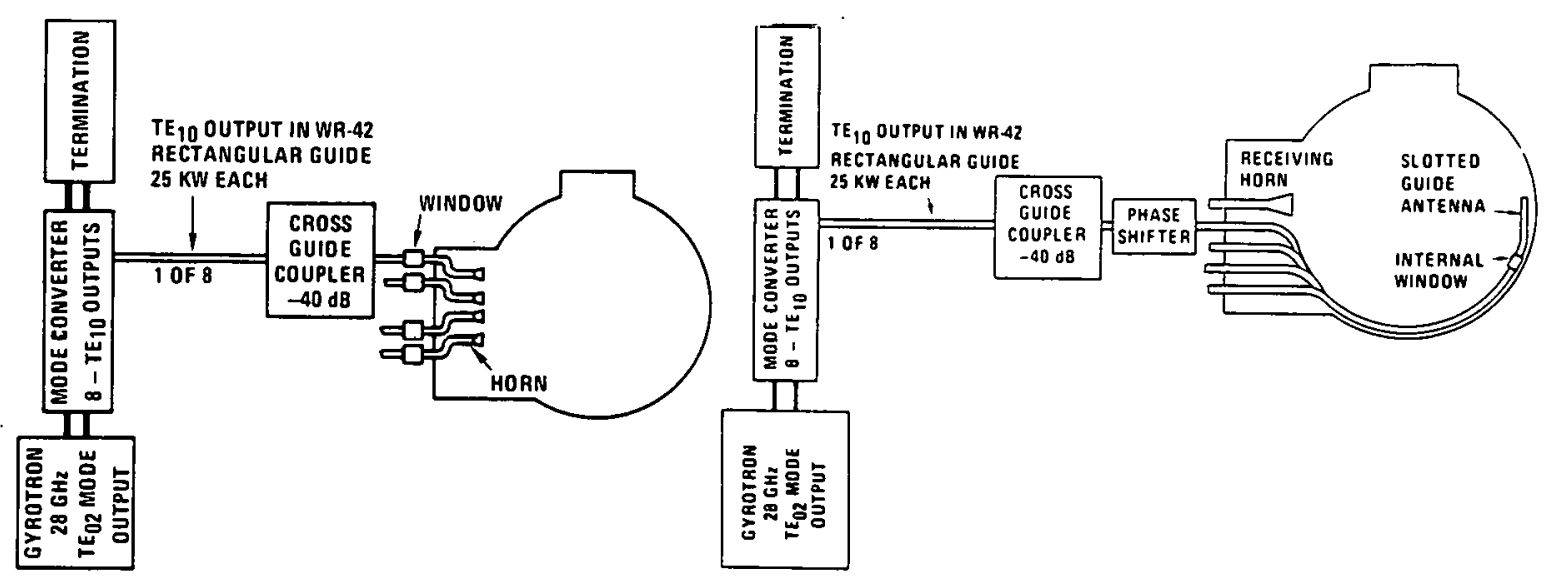

Fig. 1. Microwave transmission systems for the outside and inside launch.

$X$-ray pulse helght analysis system. Other available diagnostics were a soft X-ray PIN diode array, a second electron cyclotron harmonic radiometer, bolometers, and visible and near UV spectroscopy. Line averaged plasma density was determined by the $2 \mathrm{~mm}$ microwave interferometer, and local density was determined by the Thomson scattering system.

Outside Launch Experiments 7

The antenna for the outside launch experiments was an array of 8 horns stacked vertically in four pairs. Horn pairs were aimed alternately at $\pm 10^{\circ}$ to a major radius. The half power beam width of each horn was $\pm 8^{\circ}$, and the horns radiated with the electric field parallel to the toroldal magnetic field.

Figure 2 shows the central electron temperature measured by Thomson scattering (circles) and soft $X$-ray pulse height analysis (squares) when $110 \mathrm{~kJ}$ of $\mathrm{rf}$ power is launched into the plasma. The toroidal field is $10 \mathrm{kG}$, which places the resonance at the center of the plasma. The central density is $8.5 \times 10^{12} \mathrm{~cm}^{-3}$, which is $85 \%$ of the cutoff density of 1 $\times 10^{13} \mathrm{cul}^{-3}\left(\omega_{\mathrm{p}}^{2} / \mathrm{w}^{2}=1\right)$. The ohmic power prior to the rf is $85 \mathrm{~kW}$. The effect of the rf power is to raise the central temperature from 600 $\mathrm{eV}$ to $1000 \mathrm{eV}$. The one-turn voltage decreases by $32 \%$ due to the drop in plasma resistivity as the temperature rises.

The solid curves in Fig. 2 are the result of a transport code run which models the plasma behavior. The code uses an energy transport coefficient that varies inversely with density, and its magnitude is adjusted to fit the ohmic plasma measurements. Microwave power absorpLlou is modeled as proportional to $\mathrm{n}^{\mathrm{T}} \mathrm{e}^{1 / 2}$, in aecordance with the theory of weak absorption of the ordinary mode. Under the JFT-2 parameters, only about $30 \%$ of the power is experted to be absorbed in a single pass, but the agreement between the code run and the experiment shows that close to $80 \%$ of the power is absorbed, assuming that the temperature and density profiles were unaffected by the heating. This implies that multiple pass absorption tonk place, and that wave reflection at the plasma boundary is important.

During the $\mathrm{rf}$ heating, the line averaged plasma density is observed to drop, typically by $15-20 \%$. This effect has also been seen in ISX-B 


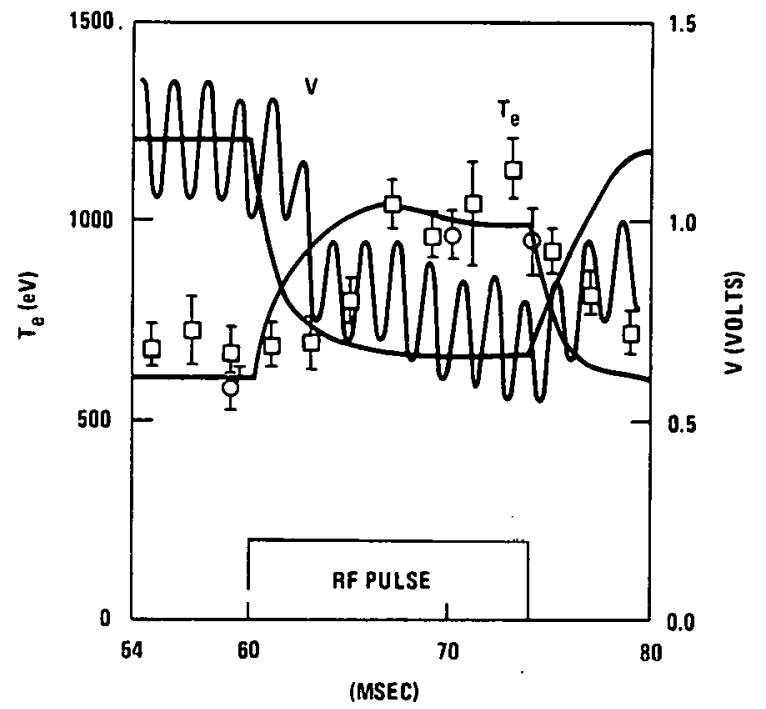

F1g. 2. Dne turn voltage $V$ and central electron temperature $T_{e}$ measured by Thomson scattering (circles) and soft X-ray pulse helght analysis (squares). The microwave power is $110 \mathrm{~kW}$, the plasma current is $70 \mathrm{kA}$, the toroldal field is $1.0 \mathrm{~T}$, and the ine-averaged density is $5 \times 10^{12}$ $\mathrm{cm}^{-3}$. Curves are predictions of empirical one-dimensional transport code.

ECH experiments ${ }^{9}$. The relative density decrease is larger at higher densities, and it takes place within a few msec of the start of the $r f$ pulse, while the Thomson scattering temperature measurements are made 10 msec into the pulse. In plotting the final steady-state heating effect as a function of central density, it is therefore important to use the reduced density during the heating rather than the initial density. In practice, this is done by multiplying the line-averaged density during the microwave pulse by a factor of 1.7 , which is the approximate ratio of peak to average density in the absence of heating.

The heating data so plotted are shown in Fig. 3. These data are consistent with simple theory: the heating falls off rapidly as the density approaches the cutoff density, $1.0 \times 10^{13} \mathrm{~cm}^{-3}$; and at low density the heating increases with increasing density. The latter observation implies that not all the power is absorbed effectively in the plasma even though the vacuum $Q$ of the plasma chamber is falrly large. Power absorbed in a resonant magnetic field region near the plasma edge is not effective in raising the central electron temperature, but it reduces the effective 0 of the cavity.

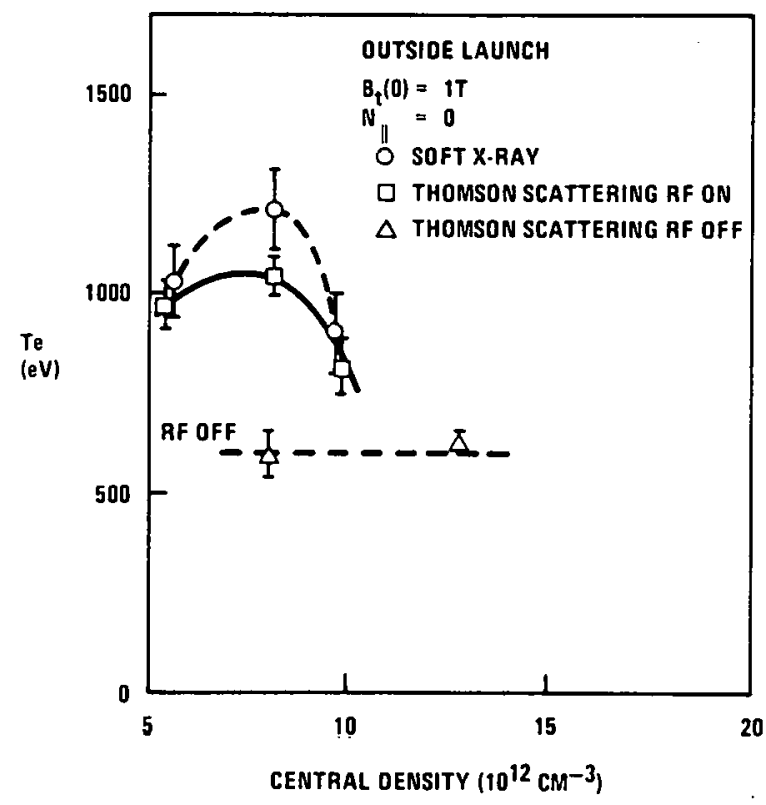

Fig. 3. Central temperature as a function of density measured 10 msec into the heating pulse for the perpendicular outside launch of the ordinary mode for a central toroidal field of 1 tesla. 
The increase in electron temperature for fixed initial density of $7 \times 10^{12} \mathrm{~cm}^{-3}$ and toroldal field of $1.0 \mathrm{~T}$ was observed to be proportional to the input microwave power, indicating that nonlinear heating effects are not important at the power used, 50 to $110 \mathrm{kl}$. The reduction in the one-turn voltage was also found to be proportional to the microwave power. Significantly, the relative line-averaged density drop when the microwave power was turned on was independent of power over that range, which implies that the density change is not dependent on the extent of the central electron heating.

When the toroidal field was varled to shift the resonance layer to different major radii, it was observed that the central heating effect was highly asymmetric. With the resonance moved $18 \mathrm{~cm}$ inside of the plasma center, the central temperature increase was nearly the same as when the resonance was at the center, while moving the resonance outside the plasma center caused a dramatic decrease in the central heating. This effect is shown in Fig. 4. A similar effect will be discussed for the Inside launch case.

Fig. 4. Relative voltage drop and central electron temperature increase as a function of central magnetic field, for initial lineaveraged density of $7 \times 10^{12} \mathrm{~cm}^{-3}$ and $85 \mathrm{kl}$ of microwave power. The locations of the cyclotron resonance on the midplane are shown in centimeters.

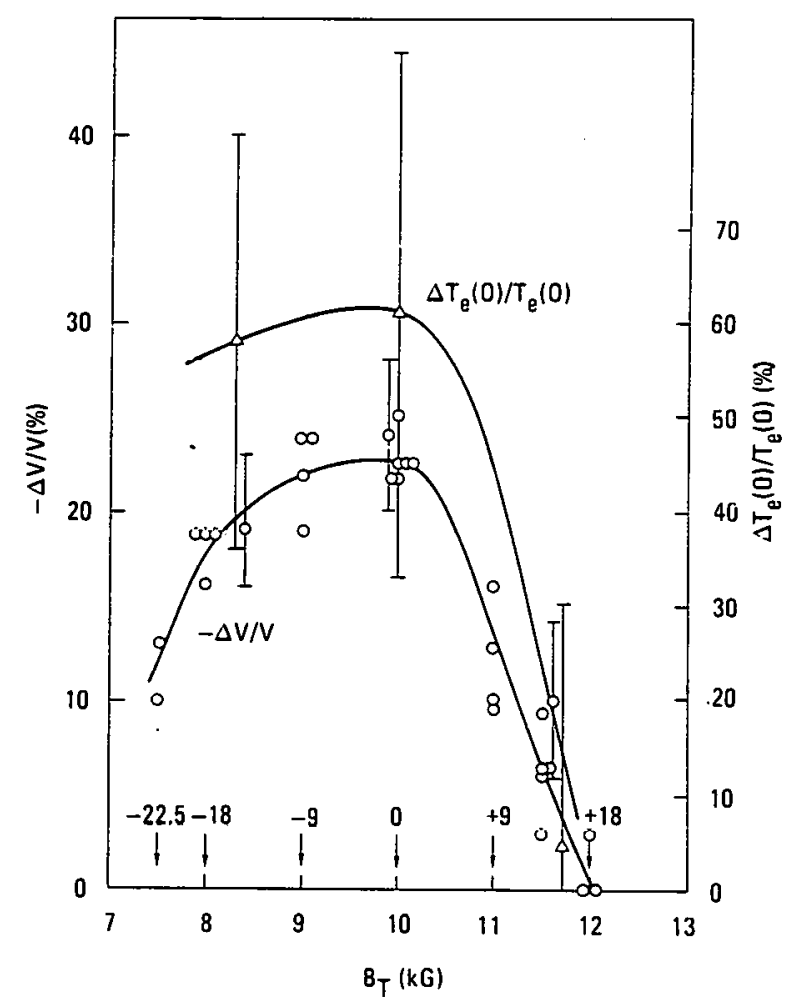

Inside Launch Experiments 8

In these experiments the antenna was a slotted waveguide phased array mounted on the inside wall (high field side) of the tokamak, centered on the midplanelo. The gyrotron output power was divided into the efght arms of a mode converter/power splitter, and each arm was routed to the antenna in fundamental mode rectangular wavegulde. Seven slots were cut in the side of each waveguide at the antenna in a vertical pattern to form a vertical broadside resonant array. The antenna radiated a narrow beam $\pm 8^{\circ}$ wide at half power, and the angular incidence of the beam could be steered relative to a major radius by adjusting the phases of the input power external to the vacuum system. To launch a pure extraordinary mode at an oblique angle, an elliptically polarized fleld is required at the plasma edge. The antenna was made to launch an 
elliptic polarization which generated primarily the extraordinary mode for $0.56<\mathrm{n}_{\|}<0.86\left(42-60^{\circ}\right.$ relative to the major radius at the location of the antenna), while for perpendicular propagation the division of power was $75 \%$ to the extraordinary mode and $25 \%$ to the ordinary mode.

The primary reason for having a steerable array was to facilitate testing the effect of launch angle on wave propagation and damping. For oblique launch angles, strong direct damping at the cyclotron resonance layer is predicted for the electron temperatures found in JFT-2, and the maximum density attainable is $2\left(1-n_{\|}{ }^{2}\right) n_{c}$, where $n_{\|}$is the local parallel index of refraction. For perpendicular launch, the damping process is expected to be mode conversion at the upper hybrid layer to slow electrostatic waves which propagate back to the cyclotron layer and are damped. For this angle $n_{\|}=0$, so the maximum attainable density is $2 n_{c}=2.0 \times 10^{13} \mathrm{~cm}^{-3}$, a factor of 2 better than that for the ordinary wave, while for oblique launch at a $42^{\circ}$ angle to the field $\left(n_{\|}=0.66\right.$ at the antenna and 0.44 at the plasma center) the maximum density is $1.6 \times$ $10^{13} \mathrm{~cm}^{-3}$. Dne purpose of these experiments was to observe whether the full predicted factor of two could be obtalned by using perpendicular launch, or whether oblique launch at somewhat lower cutoff density is preferable.

Figure 5 shows the heating results for perpendicular launch for toroidal field of $1.0 \mathrm{~T}$. The heating clearly becomes negligible for densities well below the predicted density maximum, while the mode conversion damping process would be expected to lead to heating only weakly dependent on density up to the central cutoff density of $2.0 \times$ $10^{13} \mathrm{~cm}^{-3}$.

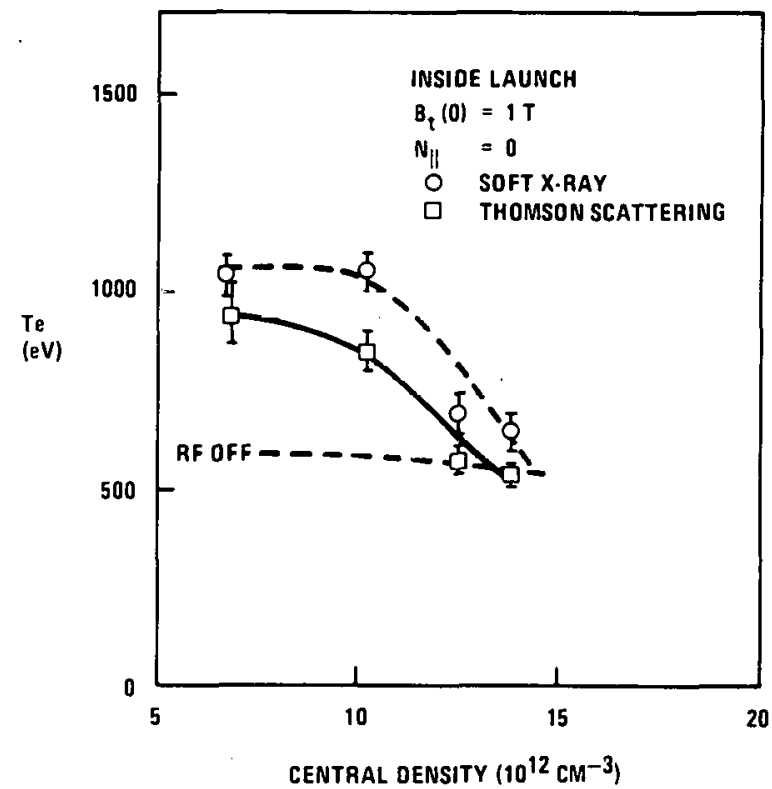

Fig. 5. Central temperature as a function of density measured during the heating pulse for the perpendicular laumcli of the extraordinary mode with a central toroldal fleld of 1 tesla.

Dther data taken at other toroidal magnetic fields suggest that the failure of perpendicular launch to heat the plasma up to the cutoff density may be due to nuulinear effects at the upper hybrid layer. At a central toroidal field of $0.86 \mathrm{~T}$, the resonance layer is located $12.6 \mathrm{~cm}$ inward of the plasma center, while the central heating is stronger and persists to higher density. In contrast, at rnontidal fields which move the resonant surface outward by a like amount the central heating nearly 
disappears. This does not seem to be an optical refraction effect since it is true even at low density. An important parameter associated with the damping that also has such an asymmetry is the position of the upper hybrid layer. Since the inverse of the damping process, used by cyclotron radiometers, does not show such behavior ${ }^{11}$, the asymmetry in the heating is may be due to a nonlinear effect. A possible candidate is direct stochastic damping near the upper hybrid layer. The asymmetry arises because as the toroldal field or the plasma density is ralsed, the upper hybrid layer moves into a lower temperature region nearer the edge. That results in both a higher local wave electric field and lower particle energy, both of which are conducive to nonlinear effects. It should be noted that the microwave power flux at the upper hybrid layer exceeds $600 \mathrm{~W} / \mathrm{cm}^{2}$ in this case. Any power damped through such effects close to the plasma boundary would be lost without contributing much to the central heating. If this is the correct explanation, then in larger tokamaks with higher edge temperatures the heating due to the mode conversion process may behave as expected from linear thenry.

For the oblique launch case, the best results were obtained at the launch angle of $42^{\circ}$ to the magnetic field at the antenna. At this angle, $80 \%$ single pass damping is expected from the direct cyclotron damping process when the electron temperature is $1 \mathrm{keV}$ and the density is $1.0 \times 10^{13} \mathrm{~cm}^{-3}$. The theoretical curve in Fig. 6 is obtained from a transport code calculation in which the cyclotron damping at each flux surface is found using the local self-consistent plasma parameters. The values of $\tau_{\mathrm{Ee}}$ and $Z_{\text {eff }}$ are chosen to fit the initial ohmic discharge. The $\tau_{E e}$ is assumed proportional to density, and the density drop, which is similar to that for the outside launch case, is added to the calculation phenomenologically. The calculation is a good fit to the Thomson scattering data and qualitatively consistent with the soft X-ray data.

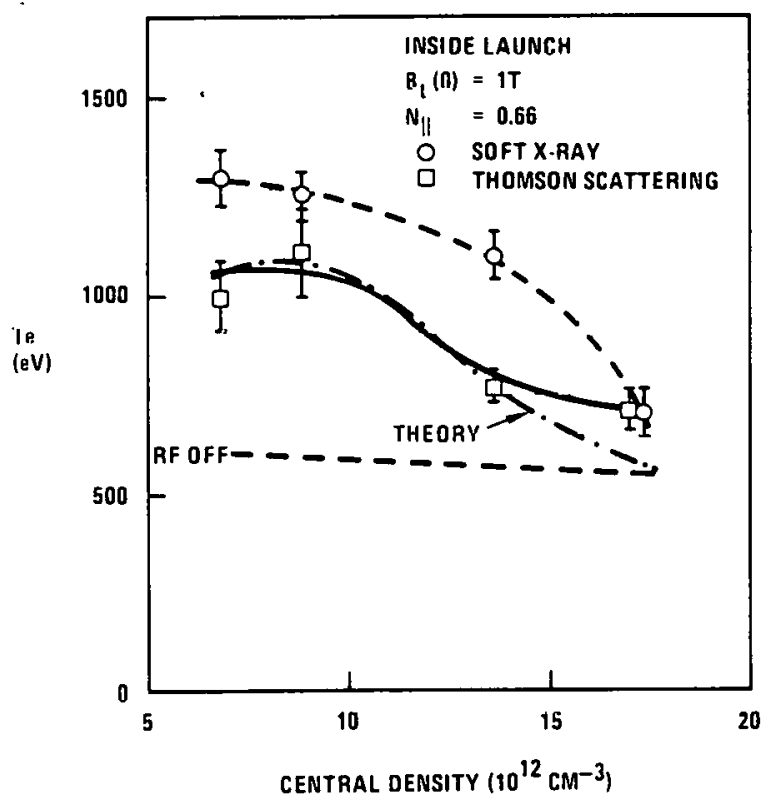

Fig. 6. Central temperature as a function of density measured during the heating pulse for the oblique launch of the extraordinary mode with a central toroidal fleld of 1 tesla.

The strongest heating under any rondition was obtained for the oblique launch case with the toroldal fleld reduced lo $0.93 \mathrm{~T}$. In this case, shown in Fig. 7 , the central electron temperature as measured by Thomson scattering rose from $600 \mathrm{eV}$ to about $1200 \mathrm{eV}$. No information was obtained ahout temperature or density profile changes, due to the 
Fig. 7. Central temperature as a function of density measured durIng the heating pulse for the oblique launch of the extraordinary mode for a central toroldal field of 0.93 tesla.

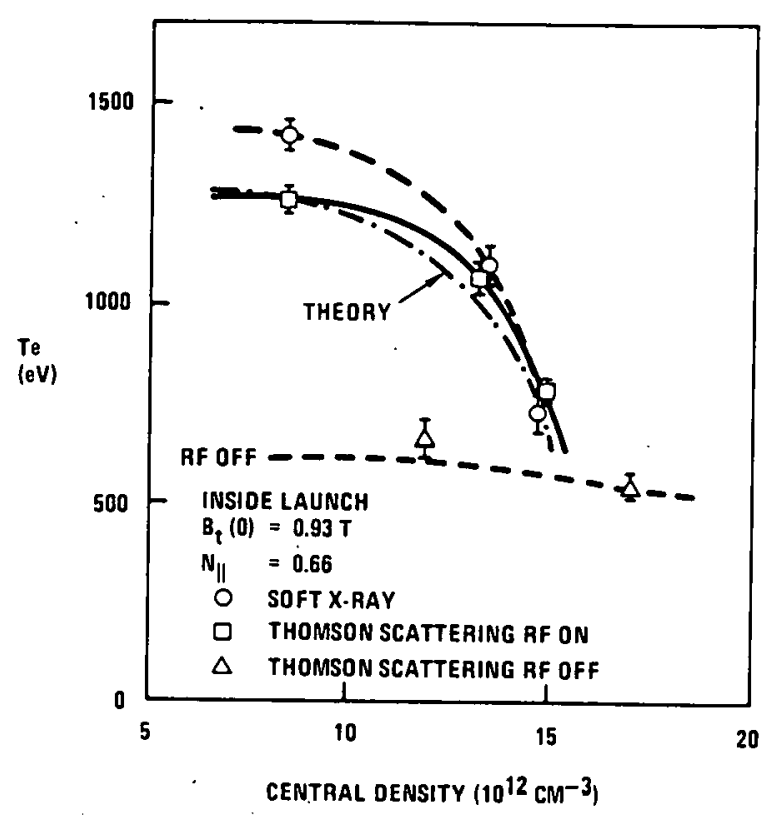

difficulty found in determining the Thomson scattering temperature at the low densities used in these experiments.

In Fig. 7, the theory curve matches the experimental data when the input power in the code is adjusted to be $100 \mathrm{~kW}$, of which 80 $k W$ is absorbed. Since the experimental input power is only $85 \mathrm{~kW}$, this implies that profile changes are taking place, other than what can be expected from the empirical electron heat diffusion coefficient, or that the efficiency of the mode conversion heating process for the power not damped in the first pass is high in the case of reduced toroidal field. For the strongest heating case, the central electron heating exceeds 7 $\mathrm{eV} / \mathrm{kW}$.

The density change when the microwave power is turned on behaves similarly to that for the outside launch. Figure 8 shows the relative local electron density change as indicated by the Thomson scattering system and the 1ine-averaged density change as determined by the microwave interferometer, as a function of the initial line-averaged density. Also shown is the change in electron temperature, which is data

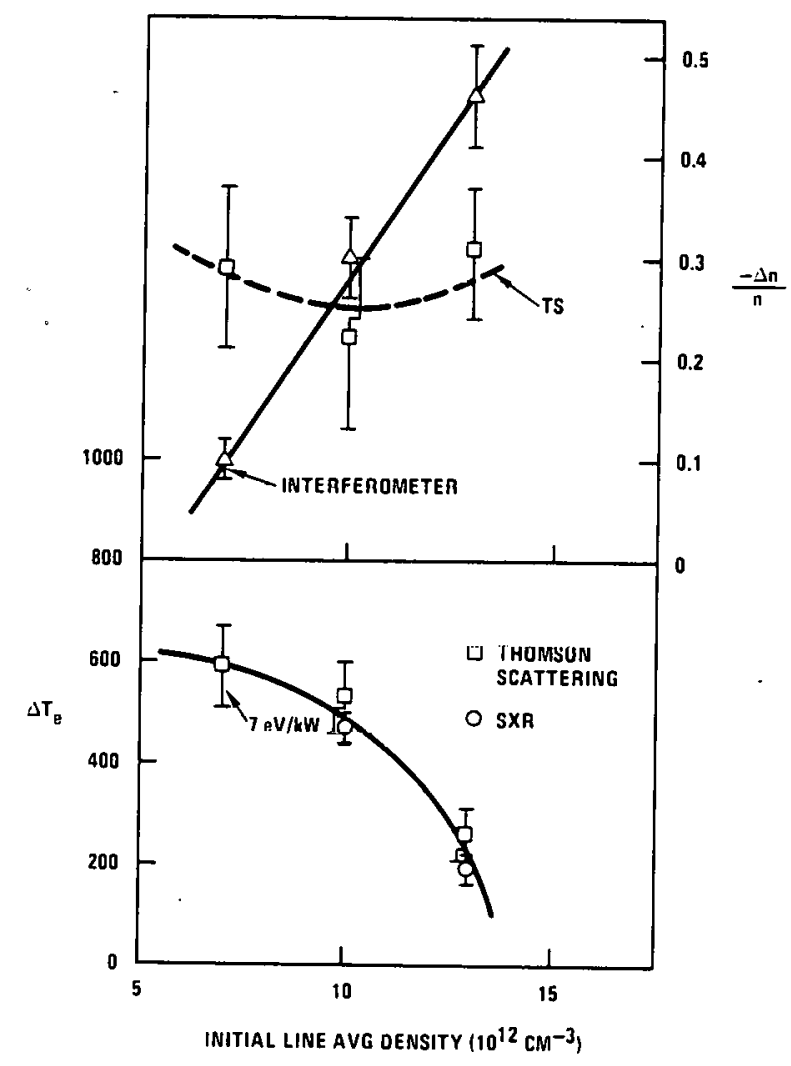

Fig. 8. Change in relative lineaveraged density (interferometer) and central density (Thomson scattering) as a function of the initial line-averaged density, for $B_{t}=0.93 \mathrm{~T}$ and $\mathrm{n}_{\|}=0.66$. Also shown is the temperature data replotted from Fig. 7 . 
reploted from Fig. 7. The change in line-averaged density is seen to be inversely correlated with the central electron heating, while the Thomson scattering data indicate little dependence on initial density or electron heating. It appears that at higher initial density, the density drop is larger and the post heating density profile is narrower, and the central heating declines. A possible explanation is that as the mlcrowave absorption near the plasma center decreases, the excess power is absorbed by plasma above and below the plasma center along the resonance, resulting in strong changes in electron temperature on the wings of the profile. This in turn affects the neutral ionization rate at the plasma edge, which may change the density and the density profile. This explanation does not explain the fairly large change seen by the Thomson scattering system at the lowest density; however, the density determination by the Thomson scattering system this low density is not very reliable.

The toroidal field dependence of the central electron heating is asymmetric for the inside launch as it was for the outside launch, as shown in Fig: 9. Much higher heating efficiency is observed when the resonance is moved to the smaller major radius side of the plasma center than when the resonance is outside the plasma center. This is also the dependence found for perpendicular inside launch.

Asymmetry with resonance location is also observed in the intensity of plasma radiation at twice the local electron cyclotron frequency, measured $5 \mathrm{msec}$ after the end of the microwave pulse. The data of Fig. 10 show very large increases in emission from the outer part of the plasma relative to the Inner part, even on the same flux surface. This indicates the formation of an enhanced high energy tail on the perpendicular Maxwellian electron distribution which is trapped in the magnetic well on the outside region of a flux surface, even though the resonance region is on the inside.

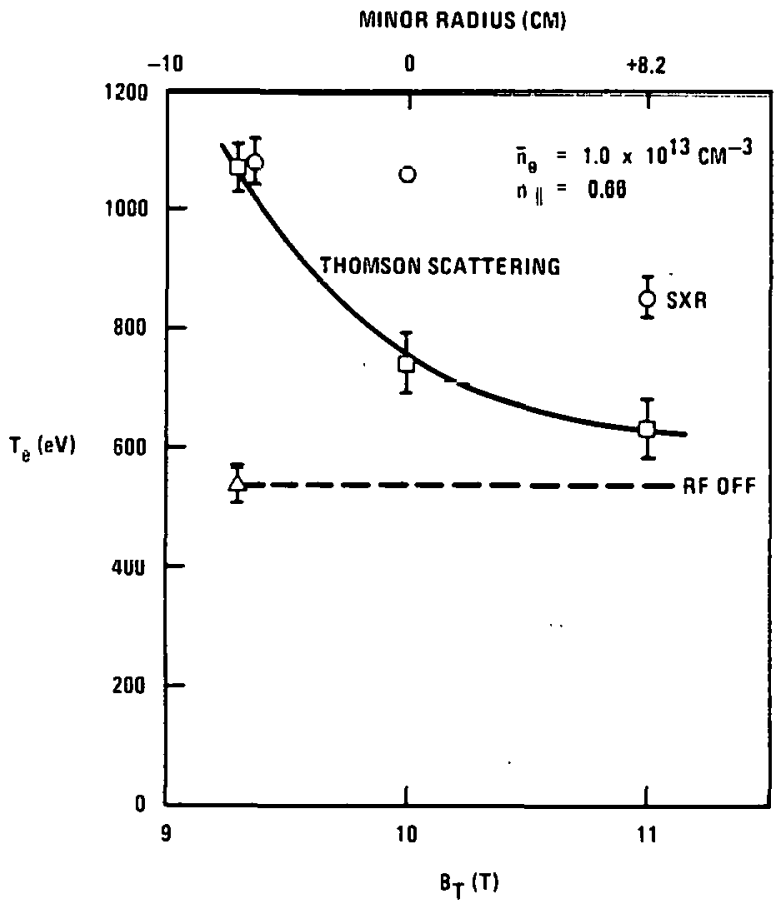

Fig. 9. Final central electron temperature as a function of central toroidal field, for a fixed initial 11ne-averaged density of $1.0 \times 10^{13} \mathrm{~cm}^{-3}$. 
Fig. 10. Emission at the second harmonic of the electron cyclotron frequency, in arbitrary units, for toroidal field of 0.9 $T$ and $1.0 \mathrm{~T}$. The initial lineaveraged density is $1.0 \times 10^{13}$ $\mathrm{cm}^{-3}$, and the measurements are taken $5 \mathrm{msec}$ after the end of the microwave pulse.

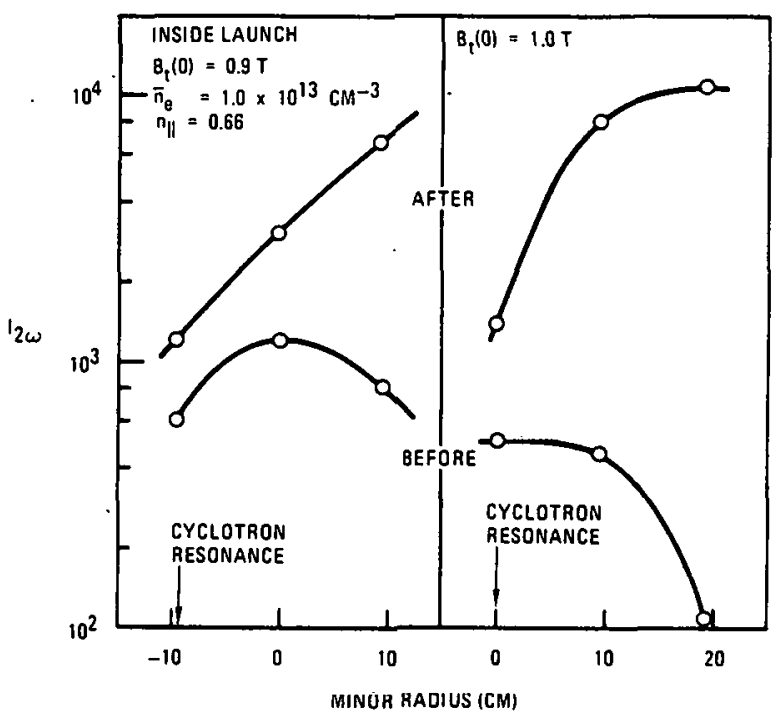

Top Launch Experiments

In an effort to obtain maximum electron heating by simply applying the largest avallable microwave power, a flexible corrugated waveguide $2.5 \mathrm{in}$. in diameter was run directly from the gyrotron to a port on the top of JFT-2, at a smaller major radius than the plasma center. The circular electric $\mathrm{TE}_{02}$ mode was used in the entire run, and the vaveguide simply terminated at a BeO window at the vacuum chamber wall. A directional coupler showed little reflected power. An absolute calibration of the forward power was not made, but gyrotron beam current and voltage measurements indicate a power output of over $150 \mathrm{~kW}$, assuming that the gyrotron efficiency was the same as it was when the mode converter/power splitter was used.

The Thomson scattering and soft X-ray diagnostics both showed a central electron temperature increase of less than $300 \mathrm{eV}$ for a toroldal field of $1.03 \mathrm{~T}$. This indicates a maximum heating efficiency $28 \%$ of that for the optimal oblique 1nside launch of the pure extraordinary mode. This experiment shows that in spite of multiple pass effects and high plasma chamber $Q$, it is possible to apply ECH power in such a manner that it is ineffective in heating the plasma.

\section{ECH for Doublet III}

A number of conclusions can be drawn from the JFT-2 experiments that are directly applicable to the design of the $2 \mathrm{MW} 60 \mathrm{GHz}$ electron cyclotron heating system for Doublet III. First, inside launch of the extraordinary mode is clearly advantegeous in obtaining heating at the highest possible density. Second, for maximum confidence the wave should be launched obliquely rather than perpendicularly, although an important goal of the program is to determine whether the theoretically predicted density limits can in fact be attained in the higher temperature plasma of Doublet III. Wave refraccion by the density gradients may well place a more restrictive limit on the maximum central density for reasonably well collimated wave patterns than the linear theory. Third, the heating efficiency can be expected to be quite high, probably in excess of $80 \%$.

The scientific goals of the Doublet III FCH project are to clarify many of the issues left undecided in the JFT-2 experiments. Improvement 
can be expected in diagnostic capabilities, due in large part to the increase by a factor of 4.6 in the density 1 imit at the higher frequency, which implies that the Thomson scattering and soft X-ray signal statistics will be greatly improved. Also, in Doublet III the electron temperature is higher, so that single pass damping will be more complete. An important issue is to verify the theory of damping of the ordinary mode, since most experiments including those on JFT-2 show much higher heating efficiency than can be expected from the theory of single pass damping; while this may be due to reflection at the plasma boundary and multiple pass absorption, it may also be due to wave damping in excess of that predicted. Another issue 1s to verify the effectiveness of ECH in strongly altering the temperature profile, which has been difficult to observe in smaller, lower density tokamaks.

The JFT-2 results have shown the importance of launching the proper mode. We expect this will be even more important in Doublet III due the large volume of low temperature, poorly confined plasma in the lower lobe which may damp microwave power not absorbed on the first pass through the upper lobe. The microwave transmission system is being designed to operate in a single mode so that efficient and effective microwave components can be designed and pure ordinary or pure extraordinary waves can be launched. Much greater emphasis is being placed on overall system efficiency, which is expected to be about $70 \%$ for power launched into the plasma in the desired mode.

The system schematic is shown in Fig. 11. Transmission takes place in the $T E_{02}$ and $T E_{01}$ modes, for which the dissipation is quite small in this overmoded waveguide (about $5 \% / 100 \mathrm{ft}$ ). The circular waveguide tapers from $2.5 \mathrm{in}$. diameter at the gyrotron to $1.094 \mathrm{in}$., which is small enough to facilitate corrugated guide bends with relatively small radius while not having excessive ohmic losses. Mitre bends were not used because they are inherently discontinuous and would require waveguide about $5 \mathrm{in}$. In diameter to reduce mode conversion to acceptable levels. Waveguide of that size wuld be too large for an inside launch.

F1g. 11. Doublet III microwave transmission system.

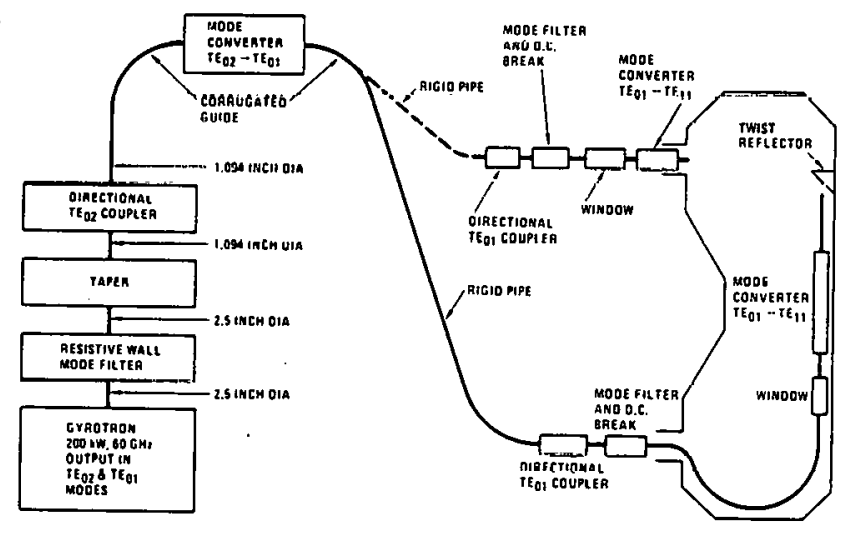

The power is converted to the $\mathrm{TE}_{01}$ mode in a mode converter with periodic axisymmetric wall perturbations, in order to minimize waveguide wall dissipation, facilitate launching of linearly polarized waves, and reduce the waveguide electric fields to the minimum (about $5 \mathrm{kV} / \mathrm{ctu}$ peak). For outside launch experiments, the power runs directly to an outside port adjacent to the plasma. which is in the upper lobe of the Doublet vessel. After passing a vacuum window of nitrogen gas cooled 
quartz, it enters a second mode converter which transforms the power to the $\mathrm{TE}_{11}$ mode with horizontal ilnear polarization. This converter is aimed at $10^{\circ}$ to a major radius, and it launches a pure ordinary mode.

For inside launch experiments, the waveguide enters through the unused lower lobe of Doublet III and runs up the inside wall. The vacuum window is located near the inner wall so that the waveguide is filled with dry nitrogen gas at atmospheric pressure at the place where it crosses the cyclotron resonance layer. The mode converter follows the window and leads to a mirror. For perpendicular injection, the mirror is planar and oriented radially, while for oblique launch the mirror is grooved in such a manner as to produce the elliptic polarization required to launch a pure extraordinary wave.

Power for the system will come from up to ten $200 \mathrm{~kW} 60 \mathrm{GHz}$ gyrotrons, with one waveguide transmission system per gyrotron. The first two gyrotrons are expected by May, 1982, with experiments to start by mid-summer.

\section{ACKNOWLEDGEMENTS}

The participants in the JFT-2 experiments were V. S. Chan and R. J. La Haye of General Atomic Company, A. Funahashi, K. Hoshino, M. Matoba, H. Matsumoto, N. Suzuk1, T. Roh, T. Toyama, T. Yamamoto, and T. Yamauchi of the Japanese Atomic Energy Research Institute, S. M. Wolfe of Massachusetts Institute of Technology, and P. C. Efthimion of Princeton Plasma Physics Laboratory. D. Remsen installed the gyrotron power sup- ply. R. Freeman and Y. Tanaka played central roles in arranging this cooperative experiment.

\section{REFERENCES}

$1_{R}$. Cano, A. Caval1o, H. Capes, Nucl. Fuston 21, 481 (1981).

$2 \mathrm{~T}$. Cho, S. Kubo, M. Ikeda, T. Saito, Y. Terumich1, Y. Hamada, S. Tanaka, Physles Letters 77A, 318 (1980).

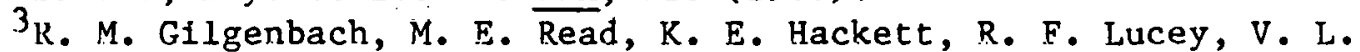
Granatstein, A. C. England, C. M. Loring, J. B. Wilgen, R. C. Isler, Y-K. M. Peng, K. H. Burrell, O. C. Eldridge, M. P. Hacker, P. W. King, A. G. Kulchar, M. Murakami, R. K. Richards, Nucl. Fusion 21, 319 (1981).

${ }^{4}$ Vincent Chan and Gareth Guest, General Atomic Report GA-Al6065 (1980); accepted for publication in Nuclear Fusion.

5 N. J. Fisch and A. H. Boozer, Phys. Rev. Letters 45, 720 (1980).

$6_{V}$. S. Chan, S. C. Chiu, J. Y. Hsu, S. K. Wong, General Atomic Report GA-Al6316; submitted for publication to Nuclear Fusion.

7 R. J. LaHaye, C. P. Moeller, A. Funahash1, T. Yamamoto, K. Hoshino, N. Suzuk1, S. M. Wolfe, P. C. Efthimion, H. Toyama, T. Roh, Nucl. Fusion 21,1425 (1981).

${ }^{8}$ C. P. Moeller, V. S. Chan, A. Funahashi, K. Hoshino, R. J. LaHaye, R. Prater, T. Yamamoto, T. Yamauchi, General Atomic Report GA-Al6.397 (1981); accepted for publication in Physics of Fluids.

${ }_{9}$ R. M. Filgenbach, M. E. Read, K. E. Hackett, R. Lucey, B. Hui, V. L. Granatstein, K. R. Chu, A. C. England, C. M. Loring, D. C. Eldridge, H. C. Howe, A. G. Kulchar, E. Lazarus, M. Murakami, J. B. Wilgen, Phys. Rev. Tetters 44, 647 (1980).

10 Charles P. Moeller, "Launcher and Transmission Systems for Electron Cyclotron Heating," these proceedings.

11 J. Hosea, V. Arunasalam, R. Cano, Phys. Rev. Letters 15, 408 (1977). 